\title{
Mortes violentas no México no século XXI: uma drástica mudança de cenário
}

\author{
Ricardo Caldas Cavalcanti Filho ${ }^{1}$
}

Resumo: O México tornou-se uma das nações mais violentas do mundo e os indicadores de violência, que até então eram baixos, alcançaram os patamares mais elevados já mensurados até então. Entre os anos de 2006 e 2012 ocorreram cerca de quarenta e sete mil homicídios relacionados ao conflito entre organizações criminosas e o Estado. Em 2010, os homicídios relacionados à guerra às drogas representaram $45 \%$ de todos os homicídios cometidos no país. De acordo com Rios, um dos autores utilizados nessa pesquisa, a cidade de Juarez chegou a marca de 216 homicídios por grupos de cem habitantes, valor superior a territórios em zona de guerra como Bagdá, a capital do Iraque. Este trabalho possui como objetivo central analisar a ascensão da criminalidade violenta, com foco nos homicídios, no México, tendo como base a tipologia de Moser, cujos fatores políticos/ institucionais, econômicos e sociais, aparecem como categorias centrais após décadas com baixos índices de criminalidade.

\begin{abstract}
Mexico became one of the most violent nations in the world and indicators of violence, which until then were low, reached the highest levels ever measured. Between the years of 2006 and 2012 there were about forty-seven thousand homicides related to the conflict between criminal organizations and the State. In 2010, drug-related homicides accounted for $45 \%$ of all homicides committed in the country. Rios says that the city of Juarez reached the mark of 216 homicides by groups of a hundred inhabitants, higher than territories in war zones such as Baghdad, the capital of Iraq. The main objective of this work is to analyze the rise of violent crime, focusing on homicides in Mexico, based on the Moser typology, whose political / institutional, economic and social factors appear as central categories. After decades with low crime rates.
\end{abstract}

\footnotetext{
${ }^{1}$ Mestrando em Sociologia no Programa de Pós-graduação em Sociologia da Universidade Federal de Pernambuco (UFPE); Pesquisador do Núcleo de Estudos e Pesquisas em Criminalidade, Violência e Políticas Públicas de Segurança (NEPS) da Universidade Federal de Pernambuco (UFPE), Recife, PE, Brasil; E-mail: ricardocaldas13@gmail.com
} 


\section{Introdução}

A vitória de Vicente Fox na eleição para a presidência do México, em 2000, foi um marco. Após setenta anos de domínio político do Partido Revolucionário Institucional (PRI), uma nova força política emergia no comando do país, tendo como centro da agenda política o aprimoramento dos instrumentos democráticos e a modernização econômica. A segurança pública passou ao largo da campanha de Fox. Até então os indicadores de violência mexicanos eram relativamente baixos, se compararmos com os vizinhos latinos. Em 2000, de acordo com dados compilados pelo Banco Mundial, o país teve uma taxa de homicídios de dez casos por cem mil habitantes, os mais baixos desde o ano de 1995, onde a taxa foi de 17. Em cinco anos, os casos de homicídios no México caíram quase que pela metade.

Já em 2006, Fox foi sucedido por um candidato de sua agremiação, o Partido da Ação Nacional (PAN), Felipe Calderón. Em um dos seus primeiros atos no controle do país, Calderón declarou guerra aos cartéis e tornou a questão da segurança pública um problema de responsabilidade federal. O exército e a Polícia Federal foram enviados para intervir nos estados onde os cartéis estavam estabelecidos e exerciam o poder local, como nos estados de Guerrero, Nuevo Laredo e Chihuahua. A partir desse momento, iniciou-se um conflito até então sem precedentes na história do país.

O México tornou-se uma das nações mais violentas do mundo e os indicadores de violência alcançaram os patamares mais elevados já mensurados. Entre os anos de 2006 e 2012 ocorreram cerca de quarenta e sete mil homicídios relacionados ao conflito entre organizações criminosas e o Estado. Em 2010, os homicídios relacionados à guerra às drogas representaram $45 \%$ de todos os homicídios cometidos no país. A cidade de Juarez chegou a marca de 216 homicídios por grupos de cem habitantes, valor superior a territórios em zona de guerra como Bagdá, a capital do Iraque (Rios, 2012).

Diante deste cenário, este artigo possui como objetivo central analisar a ascensão da criminalidade violenta no México concatenando as principais explicações presentes na literatura especializada. Com isso, buscaremos contribuir para um campo de estudos que, embora seja vasto, apresenta um escasso volume de pesquisas que articulem mais de um nível explicativo na elucidação de questões relativas à criminalidade violenta, gerando, em alguns momentos, a produção de algumas explicações que sub-representam certos fatores e/ou supervalorizam outros.

A base para este empreendimento será a tipologia de Moser (2004), cujo intento foi gerar categorias de análises que contribuem na elucidação dos tipos de violência 
impetrados e suas respectivas formas de manifestações em países Latinos. São três as categorias trabalhadas. A primeira deles é a político/institucional, circunscrita pela autora pela violência estatal e oriunda de instituições formais e informais. São exemplos manifestos: conflitos paramilitares; assassinatos políticos; conflito armado entre partidos políticos; assassinatos extrajudiciais por parte da polícia; abusos de poder judiciário etc. A segunda categoria envolve, sobretudo, ganhos materiais, sendo denominada de econômica. Está associada ao tráfico de drogas e armas, disputas territoriais, como também envolve a formação de grupos de variadas formas organizacionais, amplitudes, e estruturas, que se exteriorizam desde pequenas gangues de bairros passando por grandes cartéis. A terceira é intitulada de social, que abarca crimes interpessoais rotineiros, violência doméstica, brigas e homicídios na esfera pública.

\section{Por que o México tornou-se um país violento? Mudanças políticas, institucionais e fatores econômicos}

A literatura que buscou versar sobre a pergunta do atual tópico é praticamente consensual em relação às causas que levaram o México a tornar-se uma nação violenta. Os agentes principais são as organizações criminosas envolvidas no tráfico de drogas e o Estado. São dois os mecanismos explicativos relativos à interação entre ambos, (1) os traficantes lutam pelo controle dos mercados competitivos, e (2) o esforço do Estado para reduzir o tráfico de drogas endurecendo o cumprimento das leis (Law enforcement) (Grillo, 2012; Osorio, 2012; Guerreiro, 2013; Rios, 2013; Calderon et al, 2014; Dell, 2014).

Como observado por Osório (op.cit) e Grillo (op.cit), a luta entre os cartéis para o controle do mercado e o endurecimento por parte do Estado são fenômenos recentes na história do México. Durante décadas a relação entre o Estado e as organizações criminosas baseou-se em uma estrutura corrupta que garantia proteção aos cartéis, desde o recebimento dos carregamentos de cocaína em zonas portuárias, passando pelos corredores de transporte, as chamadas Plazas (praças), até a fronteira com os Estados Unidos.

De acordo com Rios (op.cit) e Osorio (op.cit) este sistema funcionava por que o mercado de drogas operava de forma oligopolista. Existiam apenas dois grandes cartéis, o de Sinaloa e o do Golfo, que durante muito tempo não tiveram disputas de poder internas, 
e nem lutaram entre si por territórios, além de não possuírem braços armados com táticas de confrontos paramilitares. Cada organização dominava os seus respectivos territórios, ficando livres para o estabelecimento de acordos que garantiam a operacionalização dos seus negócios.

O Estado baseava-se no estabelecimento de uma rede política de "caciques" locais, que mantinham o controle de seus estados. Tal esquema de governança marcado por um cenário de precariedade no que diz respeito à competição política e no estabelecimento de mecanismos de combate à corrupção. A estrutura de poder do PRI era corrupta, o sistema era baseado em uma rígida hierarquia de comando, o agente público que insurge-se contra esse estado de coisas era rapidamente reprimido. É dessa relação corrupta que surgem as chamadas plazas, corredores de transporte de drogas, onde os traficantes necessitavam de proteção policial. Cada plaza tinha o seu encarregado de negociar a proteção policial, que era obtida mediante ao pagamento de taxas (Grillo; op.cit).

Os aspectos que envolveram o sistema de proteção no âmbito das Plazas acabam se tornando mercadorias políticas, nos termos definidos por Misse (2007), onde agentes estatais privatizam serviços públicos e os colocam em negociação com aqueles que se configuram como público alvo. Durante muito tempo as tensões desse tipo de processo foram dirimidas, dando a entender que o México era um país pacificado.

O ponto de virada foi no ano 2000, após setenta anos hegemônicos do PRI, quando Vicente Fox, do Partido da Ação Nacional (PAN), vence as eleições para a presidência da república. O governo Fox representou o início da fissura desse esquema mantido entre o estado mexicano e os cartéis. Não houve uma declaração formal de guerra por parte do estado, mas uma mudança substancial de postura.

Para Osorio (2012), o processo de democratização além de ampliar o número de partidos políticos com diferentes visões de mundo, também aumenta o número de atores que competem entre si na promoção do bem público. Uma das consequências dessa competição é uma maior ênfase nos mecanismos de controle ao crime, violência e corrupção. O discurso repressivo na campo da segurança pública passou a ocupar os atores políticos que enxergam na implementação desses mecanismos uma oportunidade de se destacar no cenário competitivo e obter o retorno nas urnas (Downs, 1957)

A democratização no México implodiu os acordos de não intervenção do Estado nas atividades dos cartéis. As condições existentes até então demonstravam um cenário de precariedade na competição política, facilitando o trabalho das organizações criminosas. (Osório op.cit, Calderón et al,2013; Dell, 2015). Não significa dizer que no período antes 
da democratização não existiam conflitos entre o Estado e os cartéis, eles existiram. Para citar alguns exemplos, tivemos a operação condor na década de setenta e a prisão de alguns chefes de cartéis.

Como apontado por Grillo (op.cit) e Guerrero (op.cit) o grande problema desse período é que não havia um controle sistemático por parte governo mexicano. A visão que a classe política que comandava o país tinha em relação aos cartéis era a de que estes não eram inimigos do sistema, e que a violência por eles produzida eram fruto de disputas internas e não atingiram a população fora desse ciclo.

A democratização do México não modificou apenas a relação entre os cartéis e o estado, mas também entre os próprios cartéis. Anteriormente, a principal característica operacional dos cartéis mexicanos era o oligopólio, no qual cada cartel controlava o seu território, sem que houvesse uma necessidade de estabelecer disputas por posições. As intensificações das prisões dos líderes dessas organizações, dos operadores nas Plazas, e o aumento da repressão em certos territórios ocasionou o aumento da competição entre os cartéis, desencadeando uma demanda por imposição, tendo como base o uso da força, como forma de manter o negócio.

\section{Ascensão dos cartéis e suas consequências sociais}

Seguindo a investigação elaborada por Grillo (op.cit) podemos conectar que o surgimento do narcopoder mexicano está atrelado diretamente à ascensão do proibicionismo nos Estado Unidos. Os traficantes mexicanos sofreram um duro revés com a eleição de Richard Nixon nos EUA. Nixon elegeu-se com um discurso de base conservadora e extremamente negativo em relação ao consumo de drogas. Para combater tal questão, foi criada a DEA. Com um orçamento de milhões de dólares a DEA tinha como objetivo acabar com a demanda e oferta de drogas no território americano e nos países vizinhos. Sendo o principal fornecedor, o México tornou-se o alvo principal.

Os cartéis mexicanos tornaram-se organizações milionárias quando foi sedimentada uma ponte de negócios estáveis com os produtores de cocaína da Colômbia, especificamente com as FARC. Até o começo dos anos noventa os cartéis mais poderosos do mundo eram os colombianos, que tinham como principal ponto de entrada nos EUA, o estado da Flórida. Os traficantes mexicanos até então tinham um papel secundário. Esse cenário se modificou quando os cartéis colombianos deixam de ter acesso à Flórida e entram em guerra contra as instituições colombianas. 
Esses episódios enfraqueceram os cartéis colombianos, deixando um espaço vazio no posto de principal abastecedor da demanda dentro dos Estados Unidos, principalmente do mercado da cocaína. Dessa forma, desenhou-se um mapa do mercado das drogas que permanece o mesmo até os dias atuais, onde a Colômbia é a principal produtora, os países da América central funcionam como intermediários entre a Colômbia e o México, e por fim, os cartéis mexicanos controlam a distribuição para o mercado americano. São dois os cartéis que diante desse cenário, adaptaram-se melhor às exigências e emergiram como fonte de poder: o cartel do Golfo e o cartel de Sinaloa.

A primeira grande competição entre cartéis deu-se pelo controle do estado de Nuevo Laredo, dominado até então pelo cartel de Sinaloa. Nuevo Laredo é um estado chave no tráfico de drogas, pois localiza-se na fronteira com o estado americano do Texas. Esse território passou a ser disputado, a partir do ano de 2006, pelo cartel de Sinaloa e o Zetas. Essa contenda, de acordo com o Secretario Ejecutivo del Sistema Nacional de Seguridad Publica (SESNSP), teve como consequência o aumento de $100 \%$ na taxa de homicídio em Nuevo Laredo, entre os anos de 1999 e 2006.

Os Zetas foram inicialmente estabelecidos como um braço de fiscalização/ proteção para o Cartel do Golfo no final de 1990. Desertores da força de operações especiais mexicana, conhecida como GAFES (Grupo Aeromóvil de Fuerzas Especiales), tornaram-se o braço armado do cartel do Golfo. Uma vez estabelecidos, os Zetas treinaram grupos de soldados, recrutados entre as forças policiais estaduais e municipais e, em alguns casos, as fileiras do exército do México. Estes grupos iniciais de guarda-costas de elite catalisaram uma evolução da força letal e tática usada dentro submundo do crime do México. O incremento desses métodos de repressão trazidos pelos Zetas modificou totalmente as disputas entre cartéis no México. Os métodos de violência tornaram-se mais cruéis e espetaculosos. Matar tornou-se apenas um detalhe, era preciso decapitar, cortar pedaços do corpo etc. Esse padrão estabelecido pelos Zetas passou a ser seguido pelos demais cartéis que envolviam-se em disputas (Sullivan; Logan,2010).

O Zetas e suas táticas espalharam-se por outros territórios através de células autônomas. Uma dessas células foi a chamada "La familía” (a família) em Michoacán. Essa aliança foi rapidamente rompida e os Zetas e La família entraram em um confronto pelo controle pelas plazas do Estado. O resultado foi semelhante ao que ocorreu em Nuevo Laredo, uma onda de mortes, com requintes de crueldade, e um substancial incremento na taxa de homicídios local. De acordo com observatório nacional cidadano (ONC), a taxa de homicídio em Michoacán dobrou entre os anos de 2005 e 2007, indo de 20 para 40 mortes por grupo de cem mil habitantes. 
Em consonância com o incremento dos métodos de violência, o México vivenciou um processo de urbanização desordenado e, por consequência, precariamente estruturado, gerou comunidades que em sua maioria, não atuam de maneira efetiva no controle social do crime e da violência e que, portanto, geram um baixo nível de eficácia coletiva nas grandes mexicanas. A falta de controle e coesão são facilitadores para o surgimento de organizações criminosas, estruturadas e pouco estruturadas, que acabam obtendo pelo uso da força o controle dessas áreas, tornando-as pontos de venda de drogas e/ou disputas de territórios, além de aumentar a circulação de armas de fogo (Sampson; Groves, 1989; Beato Filho; Da Silva; 2014).

$\mathrm{Na}$ perspectiva de Shrik (2011), esse processo de desorganização social de longo prazo acentuou-se notadamente na década de 1990. Com o saldo de milhares de desempregados e diversas empresas retirando os seus investimentos, jovens e adultos viram-se sem emprego e perspectiva de futuro. As grandes cidades mexicanas passaram por um processo semelhante ao vivido pelas inner cities americanas, que combinou o aumento dos níveis de vulnerabilidade social e os efeitos disruptivos dos mercados de drogas. A existência de uma demanda interna aumentou as possibilidades de ganhos dos cartéis. Essas organizações também se tornaram um importante polo empregatício para essa nova camada de desviantes que estava sendo formada nas grandes cidades mexicanas. Com mais dinheiro, poder e capilaridade nas metrópoles, os cartéis mexicanos atravessaram a década de noventa e entraram no novo milênio como organizações cada vez mais fortes.

\section{A política repressiva implementada por Calderón e o aumento}

\section{da competição entre os cartéis}

Foi nesse cenário que ocorreu a sucessão presidencial. Felipe Calderón, do mesmo partido de Fox, foi o vencedor do pleito, que ocorreu no ano de 2005. Em sua primeira ação como presidente, Calderón implementou uma política de ação contra os cartéis, que envolveu a polícia federal e as forças armadas. O primeiro estado a sofrer a intervenção federal foi Guerrero. Foram destacados soldados, fuzileiros navais e policiais federais para a cidade de Michoacán (Grayson, 2010). Também sofreram intervenção federal os estados: Baixa Califórnia, Chihuahua e Sinaloa (Ríos, 2012).

Os objetivos da ofensiva federal eram (1) matar ou prender os funcionários e os chefes dos principais cartéis (2) apreender armas, drogas e veículos (3) queimar plantações de maconha e destruir laboratórios de metanfetamina (4) controlar os territórios de risco 
e assegurar a existência do pleno Estado democrático de direito nessas áreas (Osorio, 2012).

Parte da estratégia de envolver as forças federais se deu por conta do cenário de debilidade institucional que se instalou nas polícias estaduais e municipais sobretudo pela falta de ações repressivas e eficientes e pelo cenário de corrupção consolidado ao longo do tempo. Outro grave problema está localizado na ineficiência histórica do judiciário mexicano, marcado pela percepção geral de corrupção sistêmica, práticas obsoletas e autoritarismo (Shrik, op.cit).

O resultado da ação federal em termos do aumento do número de homicídios foi imediato. Como podemos observar na figura abaixo, a curva da taxa de homicídios aumentou continuamente a partir do início das ações. Entre 2006 e 2010 foram registrados 41.648 homicídios ligados ao confronto entre forças federais e os cartéis. Número bastante superior ao registrado entre 2001 e 2006 que foi de 8.901 mil homicídios. Desse total de homicídios, 82\% concentram-se em apenas quatro estados: Guerrero, Baja California, Chihuahua, Sinaloa. Justamente os quatro estados que o governo escolheu para intervir de maneira mais direta (Ríos; Shrik, 2011).

Figura 1- Evolução da taxa de homicídio no México (1980-2011)

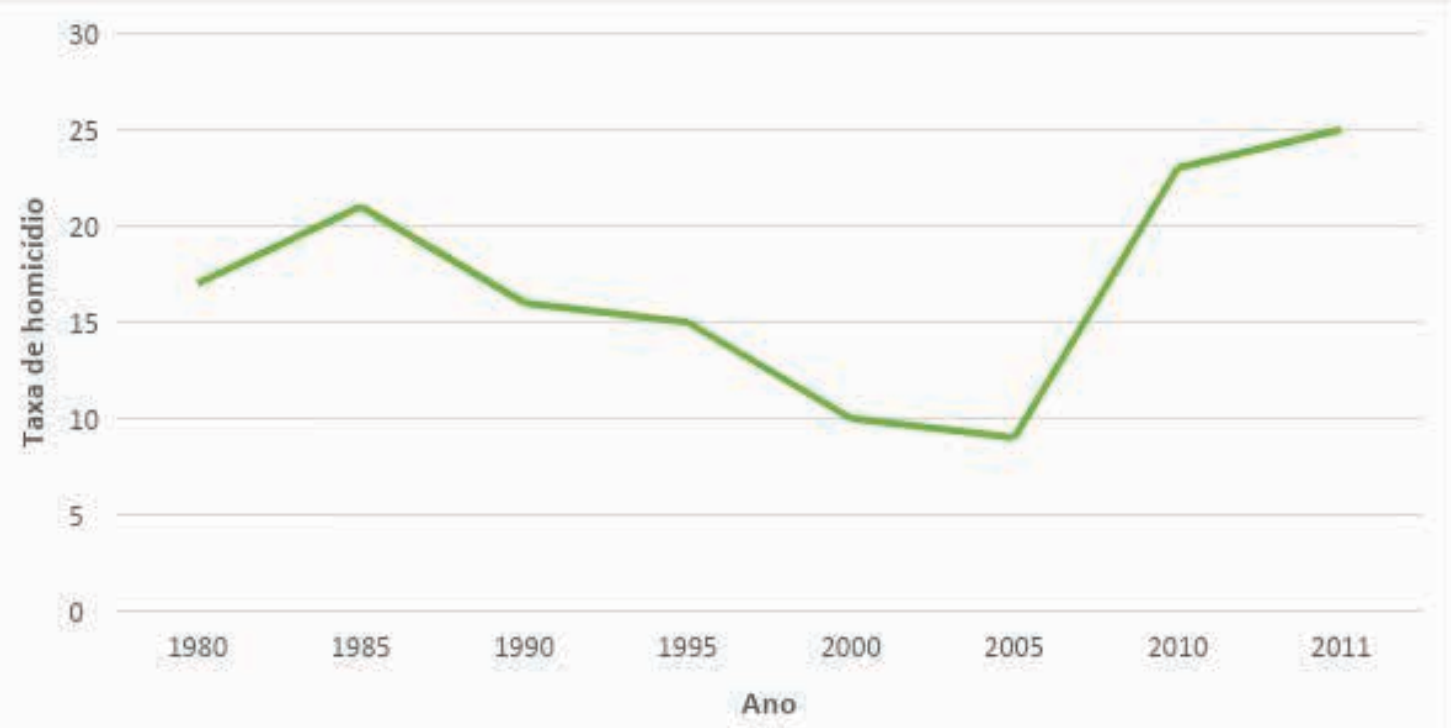

Fonte: Banco mundial

A política repressiva implementada por Calderón tornou-se alvo de um debate acerca de sua eficácia e das consequências causadas por tais ações. Para Guerrero (2011), a política de segurança adotada foi falha. O autor compara os níveis de violência antes e após a prisão de 28 líderes de cartéis. A conclusão do estudo é de que a prisão dessas figuras aumentou o nível de violência nos locais onde elas ocorreram. O processo de 
substituição desses atores é complexo. São líderes dos cartéis que estabelecem as rotas de transporte e as redes de confiança. A morte ou prisão de uma dessas figuras pode ocasionar dois tipos de disputas. A primeira é gerada por uma onda de vingança por parte dos cartéis contra as forças do Estado. E a segunda está baseada no fato de que a prisão de um líder é capaz de ocasionar uma disputa interna pelo comando vago. Como também pode ser interpretada como um sinal de vulnerabilidade por organizações rivais, que passam a enxergar uma janela de oportunidade para o início de confrontos por territórios. Um exemplo dessa situação ocorreu no cartel de Sinaloa durante a disputa entre os irmãos Beltrán e El Chapo Guzmán nas cidades de Tijuana e Juárez.

Guerrero também entende que a massiva presença de agentes federais não garante impacto no tráfico de drogas e nos crimes relacionados a essa atividade a longo prazo. É preciso que exista qualidade nas ações e a formação de um corpo policial que não esteja mergulhado em um estado de corrupção sistêmica, o que acaba dando força e poder aos cartéis, deixando a ordem pública fragilizada.

Ríos (2013) segue na mesma linha argumentativa de Guerrero, no que se refere à responsabilidade do Estado no aumento dos índices de criminalidade. Os números levantados pela autora demonstram que o aparato repressivo estatal foi responsável por $80 \%$ dos homicídios relacionados às drogas, entre 2006 e 2007. A diferença é que Rios também coloca a culpa na conta dos cartéis. Sobretudo, por conta da transformação do mercado de drogas de oligopolista para competitivo, o que gerou confrontos por territórios em diversos estados. A figura abaixo elaborada pela autora para descrever o cenário mexicano é representada por um ciclo de violência que se retroalimenta. Quando maior a repressão do Estado maior é a intensificação no grau de competição entre os cartéis e, por consequência, maior também são os níveis de violência.

Figura 2- Ciclo da violência no México

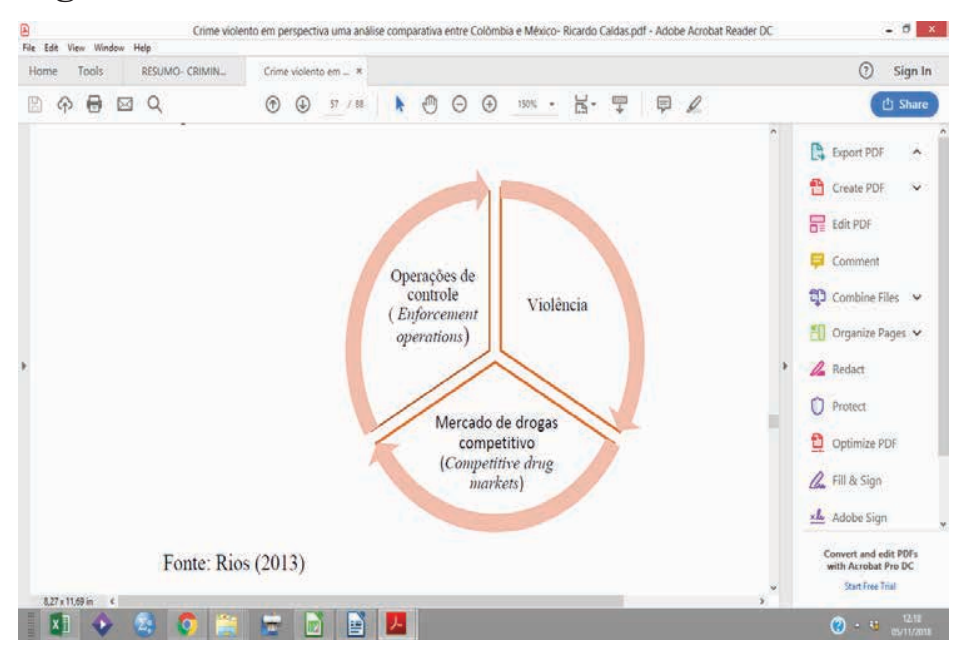

Fonte: Rios (2013) 
Outro autor que segue na mesma linha argumentativa dos anteriores é Osorio (2012). Ele entende que o Estado implementou uma tática de punição generalizada de forma pouco criteriosa contra as grandes organizações criminosas. São quatro os mecanismos que emergem na interação entre Estado e os cartéis, e entre os próprios cartéis. (1) A imposição, que se baseia em táticas coercitivas usadas pelo Estado para manter o monopólio da força. O aparato para execução de tal tarefa são: as forças militares, as polícias, os serviços de inteligência e outras estruturas de imposição da ordem. $\mathrm{O}$ principal objetivo do Estado é eliminar as organizações criminosas que afetam o seu movimento de imposição da força.

Esta tentativa de imposição estatal gera outro mecanismo, (2) a contestação. As organizações criminosas estão fundamentalmente interessadas em manter as condições estruturais que lhes permitem assegurar o retorno financeiro em suas atividades. Quem se coloca com o propósito de romper essas condições se torna alvo da força desses grupos. (3) A competição por sua vez, refere-se à luta entre cartéis na tentativa de monopolizar determinado território. E por fim, (4) a sucessão está ligada às disputas entre o altocomando de uma organização criminosa contra uma camada inferior, dentro dessa mesma organização.

Além desses quatro mecanismos, outro fator citado por Osorio é a geografia. As organizações criminosas buscam ocupar territórios chaves na produção, recebimento e transporte. Foram esses territórios que o Estado buscou, prioritariamente, se impor, e que os cartéis vão competir entre si e contra o estado. Essa é razão que justifica a grande variação subnacional da violência relacionada às drogas no tempo e espaço no território mexicano.

Uma linha dissonante na literatura é a visão de Poíré e Martinez (2011), na qual a intervenção federal não foi a principal responsável pelo aumento da violência. Os autores argumentam que o governo interveio em áreas que já eram violentas, sendo o confronto entre cartéis a principal chave analítica para explicar o cenário epidêmico de homicídios no país.

Outras linhas de estudos têm em comum o uso de técnicas econométricas para tentar medir de maneira instrumental a eficiência das linhas de ação implementadas no governo Calderón contra os cartéis. Dell (2014) tentou mensurar o efeito das eleições municipais e o grau de repressão efetiva. $\mathrm{O}$ resultado foi que em cidades onde o PAN, o partido do presidente, venceu por uma pequena margem de votos, há um padrão de ações mais repressivas por parte do chefe do executivo da localidade. 
Calderón et al (2012) buscaram medir o efeito das prisões dos chefes dos cartéis e operadores das Plazas. Os autores tiveram como base a prisão de 25 chefes e 160 operadores, entre 2006 e 2011. Os resultados alcançados mostram que as prisões dos chefes causam um aumento na violência tanto entre agentes envolvidos no tráfico como também de entre pessoas que não estão ligadas diretamente ao ramo. O que sugere que esses chefes possuem, além do poder repressivo, um forte papel na resolução de conflitos comunitários e na relação entre essas comunidades e os traficantes. Outra importante conclusão que os autores chegaram foi a afirmação que essas prisões produziram um efeito spillover entre seis e 12 meses para além do território em que elas ocorreram, mostrando a capacidade de expansão das ações dos cartéis para limites que ultrapassam o território que apenas lhe é de domínio.

Ainda no campo dos estudos econométricos, Castillo et al (2013) buscaram, além da política implementada por Calderón, explicar o incremento da violência no México pela diminuição da área de cocaína cultivada no território colombiano. A premissa utilizada no estudo é de que houve uma diminuição da oferta, com o número de áreas destinadas ao cultivo de coca incineradas na Colômbia, enquanto a demanda não diminuiu.

Esse cenário foi prejudicial aos cartéis mexicanos que passaram a conviver com a diminuição dos carregamentos de cocaína proveniente da Colômbia, forçando-os a entrar em competição entre si nos territórios de recebimento e distribuição de drogas. As estimativas dos autores indicam que a retração do fornecimento colombiano aumentou $37 \%$ a taxa de homicídios nas cidades próximas à fronteira com os Estados Unidos, e elevou em $17 \%$ a taxa de homicídio em municípios que estão $1000 \mathrm{~km}$ da divisa entre os dois países.

Essa pequena revisão da literatura que avaliou os resultados da política de segurança implementada por Calderón nos permite dizer que o modo de ação adotada pelo Estado foi um dos principais fatores que geraram o aumento da violência, em conjunto com o aumento do nível de competitividade entre os cartéis. Cabe dizer que os autores que apontam o Estado com um elemento central nesse esquema explicativo não argumentam que se o Estado não tivesse intervindo a situação do país estaria melhor. Os três grandes cartéis do país apossaram-se de determinados territórios, e neles estabeleceram o controle da ordem. Era necessário que um conjunto de ações por parte do executivo fossem impetradas. O ponto de discussão refere-se ao tipo de estratégia de intervenção que foi adotada.

De cunho estritamente punitiva, a estratégia adotada pelo executivo mexicano visou punir o maior número de organizações criminosas, sem levar em conta os efeitos 
que estas ações teriam sobre os níveis de violência. Em contraste, uma estratégia de dissuasão incide sobre o envio de mensagens a organizações criminosas para desencorajar os comportamentos e ações que têm custos mais elevados em termos de vida humana e o bem-estar social violenta. Comumente, a estratégia punitiva, procurando punir como muitos criminosos favorece a impunidade generalizada devido à dispersão das suas capacidades limitadas e recursos nos campos de aplicação jurídica e direito (Guerrero, op.cit).

Neste contexto de incerteza, criminosos não possuem incentivos para desistirem do uso da violência. Pelo contrário, como mostram os fatos, a violência gerada pelo crime organizado aumentou e se dispersou. Embora a estratégia punitiva tenha sido bemsucedida no desmantelamento de organizações criminosas, os espaços deixados foram rapidamente preenchidos por organizações menores e mais violentas.

Portanto, longe de ter espaços públicos recuperados, a atual estratégia levou a um declínio na segurança e liberdade de movimento em áreas de terra cada vez maiores. Este processo de expansão das áreas de influência do crime organizado é dramaticamente acelerado desde 2008. Finalmente, com uma estratégia punitiva o governo não pode gerir os seus recursos e capacidades de forma eficiente, tal como é aplicado em nenhuma ordem particular, sem objetivos e prioridades claras. Daí as ações decorrentes desta estratégia são frequentemente fracos e sem impacto (Guerrero, op.cit).

\section{Resultados da nova forma de atuação do governo federal e as mudanças nas formas de ação das organizações criminosas}

Passados dez anos de guerra entre os cartéis e o Estado, o pico da taxa de homicídio nacional foi entre os anos de 2006 e 2010 . Nesse período houve um aumento de $300 \%$ no número de pessoas assassinadas por grupo de cem mil habitantes, um salto de oito para 24. Após esse período crítico, houve uma retração de 50\% entre 2007 e 2013, com os números permanecendo estáveis entre 2014 e 2015 (Gagne, 2016).

Tal redução deu-se por conta do desmantelamento de alguns cartéis (Guerrero, 2016). Também houve avanços institucionais, como a reforma no poder judiciário. Tal reforma consistiu em alterações aos artigos da Constituição contendo disposições em matéria de justiça criminal e segurança pública. No início de 2000, o governo do presidente Vicente Fox (2000-2006) apresentou uma iniciativa formal para reformar o sistema em um contraditório sistema de justiça criminal, uma iniciativa que não obteve 
consenso político e foi rejeitada pelo Congresso. Esta primeira tentativa de reformar o sistema de justiça mexicano, embora falha, inspirou alguns estados de promulgar suas próprias reformas devido à ameaça do crime organizado. Durante o governo do presidente Felipe Calderón (2006-2012), uma iniciativa foi apresentada que atraiu sobre as reformas propostas anteriormente, mas contidos novas disposições destinadas a reforçar a estratégia empreendida contra o crime organizado. O congresso aprovou o pacote de reformas em 2008 e definiu um período de oito anos para a sua plena aplicação a nível nacional.

Também podemos citar como importantes avanços institucionais a criação da Comissão de Segurança Nacional, que funcionou como ente responsável por coordenar as ações no campo da segurança pública. Uma das ações de maior êxito foi o fortalecimento da divisão anti-sequestro. No campo da prevenção criminal, houve uma melhoria na geração de diagnósticos e na elaboração de informações quantitativas e qualitativas (Guerrero, 2016).

A eleição de Peña Nieto aprofundou uma mudança que já tinha começado de forma incipiente em anos anteriores. O seu governo passou a atuar de forma mais seletiva na captura dos líderes dos cartéis. Essa mudança envolveu uma redução da intensidade das capturas e outras ações contra o crime organizado. Por exemplo, nos primeiros 11 meses do governo de Peña Nieto foi uma redução de 33\% nas prisões, e metade das apreensões de armas em comparação com Calderón em 2012. O envio de forças militares e da Polícia Federal continua a ser o componente central das intervenções em todas as entidades enfrentam desafios de segurança graves. Também deve-se notar que a permanência das Forças Armadas na realização de tarefas de segurança reflete tanto o caráter limitado teve a Gendarmerie o pouco progresso no fortalecimento da polícia estadual e municipal (Guerrero, 2016).

Apesar dos avanços citados, o México ainda enfrenta diversos problemas no combate ao crime organizado. O país ainda se encontra em conflitos entre organizações criminosas por imposição em determinados territórios. Uma das principais consequências da manutenção da estratégia estatal em seguir tentando acabar com os grandes cartéis foi a fragmentação seguida de um processo e dispersão geográfica de expansão violência. As organizações que se originam dessa fragmentação, de maneira geral, não possuem a estrutura requerida para entrar no tráfico de drogas. Diante dessa limitação, as atuações desses grupos concentram-se em atividades como: roubo de automóveis, extorsões, sequestros etc.

Outra tendência que se tornou visível foi a mudança de comportamento dos cartéis. Essas organizações buscam sair do foco do aparato estatal, sobretudo na zona da fronteira 
com os Estados Unidos. O centro foi a região que passou a ser habitada pelas principais organizações criminosas do país. A dispersão geográfica teve como principal resultado a emergência de novos focos de violência, e o aumento de municípios que registraram homicídios relacionados ao tráfico de drogas. De acordo com Guerrero (op.cit), entre os anos de 2007 e 2011 o aumento esteve na ordem de $277 \%$.

Esse deslocamento geográfico tem causado novos males em várias regiões do país, especialmente com o movimento de criminosos para as periferias das cidades e localidades rurais. Fora das cidades as gangues atuam extorquindo empresários nos setores da pecuária, agricultura e mineração principalmente, que em muitos casos optaram por financiar "grupos de autodefesa" para proteger suas famílias e do patrimônio. Estes grupos não são apenas uma resposta para as atividades criminosas de organizações criminosas que afetam os interesses dos empresários rurais (agricultores, criadores de gado e mineiros), mas a consequência natural da presença limitada do Estado Mexicano em grandes áreas do país. Apesar desses grupos terem relações tênues com organizações criminosas, apenas $12 \%$ dos grupos de autodefesa estão relacionados com organizações criminosas, guerrilheiros ou paramilitares. Os confrontos entre organizações criminosas e grupos de autodefesa (ou policiais comunitários) levaram ao aumento da violência em algumas áreas rurais. Na visão de Guerrero (op.cit), isso é preocupante porque a visibilidade dos crimes cometidos no meio mundo rural é menor, dificultando uma resposta mais eficaz por parte da sociedade ou das instituições. (Guerrero; op.cit; Mazzei; 2009).

\section{Considerações finais}

Este trabalho apresenta claras limitações por se tratar de um estudo majoritariamente especulativo com déficits empíricos fator este que não garante o concatenamento das categorias que trabalhamos como correspondentes reais no desenvolvimento dos crimes violentos no cenário mexicano. Todavia, o que buscamos foi ampliar o debate e empreender uma explicação que versou sobre a questão da criminalidade violenta como sendo fomentada por desdobramentos em múltiplas esferas. O quadro abaixo representa uma síntese dos fatores que elencamos ao longo deste trabalho e suas relativas categorias. 
Tabela 1 - Síntese dos mecanismos fomentadores da criminalidade violenta e suas respectivas formas de manifestação no México.

\begin{tabular}{|l|l|}
\hline Categorias & México \\
\hline Institucional/Político & $\begin{array}{l}\text { Efeitos do processo de democratização; implosão das redes de corrupção; } \\
\text { escolha de uma estratégia punitiva via polícia e forças militares. }\end{array}$ \\
\hline Econômico & $\begin{array}{l}\text { Organizações criminosas estruturadas (Cartéis) inseridas em um mercado } \\
\text { competitivo e lutando contra o Estado. }\end{array}$ \\
\hline Social & $\begin{array}{l}\text { Desorganização social; alto poder de cooptação das organizações } \\
\text { criminosas no âmbito das grandes cidades mexicanas. }\end{array}$ \\
\hline
\end{tabular}

Fonte: Elaboração própria a partir da tipologia de Moser (2004)

Por fim, faz-se necessário destacar algumas questões importantes que não fomos capazes de delinear apontamentos no curso deste artigo e também possíveis problemas de pesquisas futuras. Pensando nos mecanismos fomentadores da criminalidade violência no Brasil, em que medida é possível estabelecer diferenciações e aproximações em comparação com o caso mexicano? Ao mesmo tempo, podemos também questionar, em que medida o atual processo de crescimento do crime organizado no país se assemelha ao que podemos observar no México, em outros termos, estaria o Brasil se tornando um Narcoestado?

\section{Referências}

BEATO FILHO, Claudio Chaves; DA SILVA, Bráulio Figueiredo Alves. Ecologia social do medo: avaliando a associação entre contexto de bairro e medo de crime. Revista Brasileira de Estudos de População, v. 30, p. 155-170, 2013.

BANCO MUNDIAL. Disponível em: http://data.worldbank.org/indicator/VC.IHR. PSRC.P5. Acessado em: 15/02/106.

CALDERÓN, Gabriela et al. The temporal and spatial dynamics of violence in Mexico. University of California in San Diego (UCSD).

CASTILLO, Juan Camilo; MEJIA, Daniel; RESTREPO, Pascual. Illegal drug markets and violence in Mexico: The causes beyond Calderón. v. 3, n. 10, p. 2013, 2013

DELL, Melissa. Trafficking networks and the Mexican drug war. The American Economic Review, v. 105, n. 6, p. 1738-1779, 2015. 
DOWNS, Anthony. An economic theory of political action in a democracy. Journal of Political Economy, v. 65, n. 2, p. 135-150, 1957.

GAGNE, David. Latin America Homicide Round-up. InSight Crime (2016).

GRILLO, Ioan. El Narco: inside Mexico's criminal insurgency. Bloomsbury Publishing USA, 2012.

Publishing, 2011.

El narco: the bloody rise of Mexican drug cartels. Bloomsbury

GUERRERO, Eduardo. La inseguridad 2013-2015!. Nexos, 1 jan 2016. Disponível em: http://www.nexos.com.mx/?p=27269. Acessado em: 15/03/2016.

La raíz de la violencia., Nexo, 1 Jun 2011 Disponível em: http://www. nexos.com.mx/?p=14318 . Acessado em: 11/05/2016.

MAZZEI, Julie. Death squads or self-defense forces?: how paramilitary groups emerge and challenge democracy in Latin America. Univ of North Carolina Press, 2009.

MISSE, Michel. Mercados ilegais, redes de proteção e organização local do crime no Rio de Janeiro. Estudos avançados, v. 21, n. 61, p. 139-157, 2007.

MOSER, Caroline; HOLLAND, Jeremy. Urban poverty and violence in Jamaica. World Bank Publications, 1997.

.. Asset-based approaches to poverty reduction in a globalized context.

2006.

.. Urban violence and insecurity: an introductory roadmap. 2004.

OBSERVATÓRIO NACIONAL CIDADANO. Disponível em: http://onc.org.mx/. Acessado em: 05/08/2016.

OSORIO, Javier. Dynamic and structural determinants of drug violence in Mexico. In: Violence, Drugs and Governance: Conference on Mexican Security in Comparative Perspective. 2011.

.Democratization and Drug violence in Mexico. Notre Dame: University of Notre Dame), unpublished typescript, 2012

POIRÉ, Alejandro; MARTINEZ, Teresa. Los homicidios y la violencia del crimen organizado. Nexo $(01 / 02 / 2011)$.

RÍOS, Viridiana. Tendencias y explicaciones al asesinato de periodistas y alcaldes en México: El crimen organizado y la violencia de alto perfil. Las bases sociales del crimen organizado y la violencia en México, Centro de Investigación y Estudios en Seguridad (CIES), Secretaría de Seguridad Pública, México, 2012.

. Why did Mexico become so violent? A self-reinforcing violent 
equilibrium caused by competition and enforcement. Trends in organized crime, v. 16, n. 2, p. 138-155, 2013.

.; SHIRK, David A. Drug violence in Mexico: Data and analysis through 2010. Trans-Border Institute, University of San Diego, 2011.

SAMPSON, Robert J.; GROVES, W. Byron. Community structure and crime: Testing social-disorganization theory. American journal of sociology, v. 94, n. 4, p. 774-802, 1989.

SECRETARIO EJECUTIVO DEL SISTEMANACIONALDE SEGURIDAD. Disponível em: http://secretariadoejecutivo.gob.mx/index.php. Acessado em: 05/08/2016.

SHIRK, David A. Justice reform in Mexico: change \& challenges in the judicial sector. SHARED RESPONSIBILITY, p. 205, 2010.

Relations, 2011.

. The drug war in Mexico: confronting a shared threat. Council on Foreign

SULLIVAN, John P.; LOGAN, Samuel. Los Zetas: Massacres, Assassinations and Infantry Tactics. Security Solutions International, November, v. 24, 2010.

Recebido em 21/11/2018 